\title{
Citizen Science - An examination from the viewpoint of an ordinary person
}

\author{
Gotthard Weiss ${ }^{a}$, \\ aNone, \\ Kaiserstrasse 44 / 2 / 1, 1070 Vienna, Austria \\ E-mail: gotthard@weiss.net
}

In this article I will reflect the relevance of questioning from ordinary persons in comparison to possible expections of scientists, especially compared to defintions of citizen science.

Thereby, I wanted to show the difference between so-called ordinary questions in regard to scientific questions - and how this could lead to misunderstandings, but - by solving it - could encourage other ideas of distributing tasks in citizen science.

In the end there will still be questions, left open for your own imagination. 


\section{Introduction}

All literature written about having non-scientists participate in scientific research I am aware of are written from the standpoint of someone working in universities or are at least affiliated to a scientific organization. A good summary for definitions and particularly the difference between participation and co-creation in citizen science can be found in Vohland, et al., 2021, markedly in chapter 11, p. 199ff. Therefore, this article will not add anything new to this scientific research but instead give some suggestions on how things can be seen differently.

\section{Coming from questions to a viewpoint}

\subsection{Questions of non-scientists}

According to Wikipedia "a question is an utterance which typically functions as a request for information." ${ }^{11}$ This definition is very generally; therefore, I want to make some clarifications.

At first: can or should it depend on the person asking, only questions asked by scientists being scientific questions? But wouldn't that mean that ordinary people cannot even contribute to research - at least not in a co-creation process? Or that a literal repetition by a scientist changes the nature of the question?

Therefore, one criterion should be in what context the question is being asked. An example could be the question: "who won the soccer Champion League in 2018?" That sounds ordinary as soccer can be, but what if the question is asked in context of scientific research? If someone wants to find out whether there is a relationship between socio-economic factors and success in soccer competitions?

One aspect of the given context is the viewpoint of the inquirers and their self-perception of their own role in this process. For example, asking the question "what is teabutter?" not even thinking of furthering scientific research with it as one is a "simple" hobby cook. This could even influence the answers - the same cook, talking confidently in a room full of other hobby cooks, could be fearful in presence of a scientist. This could be a reason for co-creation or collaborative processes not working as expected, as for example in Heinisch, 2019. Answering the same question in the context of scientific research could be a hugely different beast.

This is one aspect of the gap between the ivory tower of science and ordinary people. Another is that the context of a question is political or even anti-scientific, for example the issue of conspiracy theories. As Ball \& Maxmen, 2020, state in their article about Covid-19 conspiracies: “The problem isn't a lack of facts. It's about what sources people trust." Therefore, reducing the gap is not as easy as it sounds at first.

\footnotetext{
${ }^{1}$ See en.wikipedia.org/wiki/Question, retrieved on January, 18, 2021.
} 


\subsection{Questions in the context of citizen science}

Assuming that questions are asked in a scientific context by a citizen, this does not automatically mean that it is relevant for citizen science. For elaborating on that I refer to the definition in Vohland et al., 2021, p. 20, that there is a differentiation between public understanding and scientific knowledge.

In the aspect of public understanding every question is worth answering and I am even sure that an astronomer will answer the first time someone wants to know why the earth is flat. But what about the thousandth person confronting him/her that the earth is flat? Do not expecting from the most good-natured person to stay cool with such questions. And again, this leads us astray from citizen science and into the topics of education systems, forgotten knowledge and even into the questions of self-awareness and someone's correct self-assessment of his or her knowledge.

Therefore, for setting up a citizen science project it must be in the context of broadening scientific knowledge. This means one must get from one or more questions to setting up a matching scientific research design - already indicating the need for qualified scientists. Whether the special research design is of contributory citizen science or co-creation and participatory approaches like described in Vohland et al., 2021, p. 201, is its own topic and here for the merits of the professionals.

This also means that such questions could lead to a research design that does not even include a citizen in its realisation. Even the perception of the citizen can change based on the research design, for example again referring to Heinisch, 2019 and the question of the month: it could as well be a novel issue for linguistics making it a co-creation design, but it could as well be that the question of the month is already answered, and the design is asking whether laypeople can be taught the methods of linguistics making the citizen to the object of the research.

\subsection{From ordinary questions to answers}

Unfortunately, because of my understanding there is a difference between questions asked by citizens and research designs of citizen science projects. Hopefully, I have showed that a "Citizen Science"-only approach is not enough.

On the role of the citizens:

- Getting an answer to their questions!

- But should that be all in the scientific process?

Coming to an answer could come by different means:

- from professional scientists, being it in their role as lecturers, researchers, citizen science project leaders; or

- from science communicators,

- educational institutions, or 
- all other persons/institutions summarised as "scientific community".

- But the answers could indeed certainly come from

○ well-educated laypeople, or what I would call hobby scientists,

- someone working in this area, but a non-scientific company,

- someone participating in citizen science projects,

$\circ$ or by reading books, magazines, and websites.

That list is far from all-embracing, it should only show the complexities of the issue and there is a wide variety of persons and organisations bringing answers to ordinary people. Therefore, in some respects this is already too much, and one does not even know whom to address with owns' questions. On the other hand, it is too less as some socio-economic groups are not reached by them (e.g., not even by adult education centres, Volkshochschulen in Austria).

In contrast there are ordinary people who could be more involved in scientific research. In brewing science there is ongoing research into wild yeasts like in R. Preiss et al., 2018. The starting point for it a hobby brewer that tried to re-brew traditional Norwegian beers, see L.M. Garshol, 2000. Therefore, now most citizen projects originate from universities and few from nonscientific associations. So how could a citizen start such a project - not only being a guinea pig / data collector, but more integrated into the process - perhaps even as project leader.

Bringing this together it would suggest that there is a need for a low-level entry point - even lower than Volkshochschulen - to bring some groups nearer to science but also some transferring up the scientific professions for setting up new research projects (starting from the initial question).

In companies there are often hotlines set up for answering user questions. There would be different levels starting with a first level answering easy questions up to the last level where the experts are answering them. In IT service management there is the de-facto standard ITIL which differentiates between "Run-the-Company" and "Change-the-Company". For the issue of answering scientific questions this analogy could be translated to a similar system: as every small village now has a voluntary fire brigade this could be something like a voluntary science brigade consisting of hobby scientists (perhaps as employees of the municipal office, thereby hopefully solving trust issues). The analogy for "Run-the-Company" could be answers to questions that are already known, whereas change would be new research.

Another possibility could be events that are not even mentioning science but are still educational endeavours to bring people nearer to science. These events being still more subliminal in addressing attendees than in Volkshochschulen or in the public parts of citizen science conferences.

\section{Conclusion}

My conclusion is that I have no conclusion - just questions and more questions. But as the goal was not to answer these questions, but instead show the differences that ordinary people can have to scientists in seeing these issues; I still conclude this article. 


\section{References}

[1] K. Vohland, A. Land-Zandstra, L. Ceccaroni, R. Lemmens, J. Perelló, M. Ponti, R. Samson, K. Wagenknecht, The Science of Citizen Science, Springer International Publishing, Cham 2021.

[2] B. Heinisch, Comparison of co-created and collaborative approaches to citizen science adopted by the citizen linguistics project 'On everyone's mind and lips - German in Austria', in proceedings of $5^{\text {th }}$ Austrian Citizen Science Conference 2019 PoS (ACSC2019).

[3] L.M. Garshol, Historical brewing techniques: the lost art of farmhouse brewing, Brewers Association, Boulder 2000.

[4] R. Preiss, C. Tyrawa, K. Krogerus, L.M. Garshol, G. van der Merwe, Traditional Norwegian Kveik are a genetically distinct group of domesticated saccharomyces cerevisiae brewing yeasts, Frontiers in Microbiology 9 (September 12, 2018): 2137, Lausanne 2018.

[5] P. Ball, A. Maxmen, The epic battle against coronavirus misinformation and conspiracy theories, Nature 581(7809): 371-374 2020 05, San Francisco 2020. 